\title{
MYOCARDIAL TISSUE ENGINEERING WITH AUTOLOGOUS MYOBLAST IMPLANTATION
}

Julia Dorfman, MD

Minh Duong, BSc

Audrius Zibaitis, MSc, MD

Marc P. Pelletier, MD

Dominique Shum-Tim, MD

Carlos Li, MD

Ray C.-J. Chiu, MD, PhD
Objective: Implanting myoblasts derived from autologous skeletal muscle, that is, satellite cells, for myocardial replacement has many advantages when compared with implanting either fetal cardiac myocytes (ethical and donor availability issues) or established cell lines (oncogenicity). Furthermore, autologous myoblasts do not require immunosuppression. The feasibility of satellite cell differentiation into muscle fibers, after implantation into the myocardium, was confirmed by means of a unique cell-labeling technique. Methods: Myoblasts (satellite cells) isolated from the skeletal muscle of adult rats are labeled with 4',6-diamidino-2-phenylindone, which binds to DNA and to the protein tubulin to form a fluorescent complex, and implanted into the left ventricular wall of isogenic rats. The specimens are harvested 1 to 4 weeks after myoblast implantation. Histologic sections are examined under a fluorescent microscope. Results: The labeling efficiency of satellite cells with 4',6-diamidino-2-phenylindole is nearly 100\%. In 4 specimens, the progressive differentiation of implanted myoblasts into fully developed striated muscle fibers can be observed. Conclusion: Our earlier studies of autologous myoblast implantation into the cryoinjured myocardium of dogs suggested that these cells could differentiate into cardiac myocytes. However, it had been difficult to firmly establish these findings with the use of cell markers, thereby proving that the neomyocardium had indeed been derived from the implanted myoblasts. In this study, using 4',6-diamidino-2-phenylindole as a satellite cell marker, we were able to demonstrate that the implanted satellite cells did in fact differentiate into fully developed, labeled muscle fibers. Because of the obvious advantages of using autologous donor myoblasts, the clinical application of this approach may provide a novel strategy for the future management of heart failure. (J Thorac Cardiovasc Surg 1998;116:744-51)
Therar he lack of regenerative ability of adult mammalian myocardium is a well-established fact. ${ }^{1,2}$ Stem cells are absent from the myocardium, and the mature cardiac myocyte is a terminally differentiated cell that has been permanently withdrawn from the cell cycle. For these 2 reasons, injury to the myocardium results in an irreversible loss of cells and the injured area is replaced by scar tissue.

From the Division of Cardiothoracic Surgery, McGill University, Montreal, Quebec, Canada.

Read at the Seventy-eighth Annual Meeting of The American Association for Thoracic Surgery, Boston, Mass, May 3-6, 1998.

Received for publication March 26, 1998; revisions requested May 18, 1998; revisions received July 3, 1998; accepted for publication July 20, 1998.

Address for reprints: R. C.-J. Chiu, MD, PhD, Suite C9-169, The Montreal General Hospital, 1650 Cedar Ave, Montreal, Quebec, Canada H3G 1A4.

Copyright $(1998$ by Mosby, Inc.

0022-5223/98 $\$ 5.00+0 \quad \mathbf{1 2 / 6 / 9 3 2 9 6}$
Skeletal muscle, however, is able to regenerate after injury because of the presence of satellite cells. The satellite cell is a morphologically undifferentiated cell that lies dormant between the plasma membrane and basal lamina of mature skeletal muscle. ${ }^{3}$ When activated by appropriate stimuli, satellite cells proliferate and differentiate into new skeletal muscle fibers. We have been investigating "cellular cardiomyoplasty," that is, the possibility of using satellite cells to regenerate myocardium. ${ }^{4-6}$ If successful, myocardial replacement with autologous skeletal muscle-derived myoblasts has many advantages when compared with other approaches for myocardial regeneration. Autologous myoblasts do not require immunosuppression; there is no potential for malignant transformation (which is a risk when established cell lines are used); and ethical and donor availability issues are not a concern (eg, use of fetal cardiomyocytes). Our hypothesis is that satellite cells transplanted into the myocardium will undergo "milieudependent" differentiation into cardiac myocytes. ${ }^{6}$ 
Our previous work of implanting autologous satellite cells into cryoinjured canine myocardium demonstrated the presence of striated muscle fibers at the implant sites. ${ }^{4}$ This muscle showed morphologic characteristics of cardiac myofibers, such as the centrally located nuclei and intercalated disks. Nevertheless, our earlier attempts to use a number of cell markers, such as ${ }^{3} \mathrm{H}-$ thymidine and the $l a c Z$ reporter gene, in an attempt to confirm that such putative "neomyocardium" indeed originated from the implanted myoblasts, had not been entirely successful. In the present study, the satellite cells were labeled with 4',6-diamidino-2-phenylindole (DAPI), a fluorescent dye that binds to both doublestranded DNA (dsDNA) and the protein tubulin. ${ }^{7-9}$ This labeling method enabled us to successfully follow, in vivo, the full differentiation of satellite cells at the implant sites.

\section{Materials and methods}

The animal model. As stated earlier, our goal is to study the feasibility of autologous myoblast implantation for myocardial regeneration. In our previous canine studies, myoblasts harvested from an animal were implanted into the myocardium of the same animal. In the present study, the less expensive but smaller isogenic rats were used as donors and recipients, since as in the autoimplants, this model obviates the need for immunosuppression.

Thirty male Lewis rats weighing 225 to $250 \mathrm{gm}$ were used in all experiments. As described in detail below, hind limb skeletal muscle was explanted from the donor rats and used as a source of satellite cells. The satellite cells were expanded in culture for 7 to 10 days and labeled with DAPI just before implantation into the myocardium of isogenic recipient rats. One to 4 weeks after implantation, the animals were killed and hearts removed for histologic analysis. The entire left ventricle was processed into $5 \mu \mathrm{m}$ sections and every second section examined under the fluorescent microscope. All animals received humane care, and all experiments were performed according to the "Guide to the Care and Use of Experimental Animals" of the Canadian Council on Animal Care and the "Guide for the Care and Use of Laboratory Animals" (NIH publication No. 85-23, revised 1985).

Skeletal muscle explantation and satellite cell isolation. After overdose with pentobarbital $(100 \mathrm{mg} / \mathrm{kg}$ given intraperitoneally) (MTC Pharmaceuticals, Cambridge, Ontario, Canada), the skeletal muscle of both hind quarters of adult rats was excised. The muscle was rinsed with $70 \%$ ethyl alcohol for 30 seconds and then rinsed with $150 \mathrm{~mL}$ of Hanks balanced salt solution (Gibco, Grand Island, NY). It was then minced with scissors until a homogeneous mass was obtained. After addition of $150 \mathrm{~mL}$ of Hanks balanced salt solution, muscle fragments were sedimented at $540 \mathrm{~g}$ for 1 minute. The supernatant was discarded. This step was repeated 2 more times. The specimen was then incubated with $1 \%$ collagenase (Sigma Chemical Co, St Louis, Mo) and 0.2\% type 1-S hyaluronidase in M199 solution (Gibco), supple- mented with $5000 \mathrm{U} / \mathrm{mL}$ penicillin and $5000 \mu \mathrm{g} / \mathrm{mL}$ streptomycin (Gibco) for 15 minutes at $37^{\circ} \mathrm{C}$ in a shaker bath. Remaining muscle mass was then spun at $540 \mathrm{~g}$ for $10 \mathrm{~min}$ utes. Released connective tissue elements were aspirated with the supernatant and discarded. The muscle fragments were then incubated with a $1 \%$ pronase solution (Sigma) for 15 minutes at $37^{\circ} \mathrm{C}$ to release satellite cells. The product obtained was sedimented at $540 \mathrm{~g}$ for 10 minutes and only the supernatant containing released satellite cells was saved for further manipulation. Fetal bovine serum (Gibco) was added to the supernatant to halt further enzymatic cleavage processes. The remaining tissue debris was separated from cells by spinning the cell suspension at $775 g$ for 15 minutes. The collected cell pellet was washed and resuspended in the same manner 4 times.

To purify the cell culture from fibroblasts present in the final cell pellet, we used the density centrifugation method described by Yablonka-Reuveni and Nameroff. ${ }^{10}$ In brief, the cell suspension was layered on $20 \%$ colloidal polyvinylpyrrolidonecoated silica (Percoll; Sigma), which itself rests on a $60 \%$ Percoll layer. The whole liquid structure was centrifuged at $15,000 \mathrm{~g}$ for 5 minutes. The cell layer obtained at the interface of the $20 \%$ and $60 \%$ Percoll concentrations consisted mostly of satellite cells, whereas the majority of fibroblasts and other cells were situated within other layers at different levels. Retrieved satellite cells were counted on a hematocytometer and their viability assessed by the trypan blue exclusion test.

Satellite cell plating and passaging technique. Isolated satellite cells were plated on $60 \mathrm{~mm}$ polystyrene tissue culture dishes (Corning, Inc, Corning, NY), which were coated in advance with a layer of laminin (Sigma) to promote satellite cell adherence. The plating density ranged from $5.0 \times 10^{5}$ to $7.5 \times 10^{5}$ cells per culture dish. Growth medium, each 100 $\mathrm{mL}$ composed of $82 \mathrm{~mL}$ of M199, $7.4 \mathrm{~mL}$ of minimal essential medium (Sigma), $10 \mathrm{~mL}$ of fetal bovine serum, 5000 $\mathrm{U} / \mathrm{mL}$ of penicillin, $5000 \mu \mathrm{g} / \mathrm{mL}$ of streptomycin, $250 \mu \mathrm{L}$ of amphotericin $\mathrm{B}$, and $40 \mu \mathrm{L}$ of gentamicin, was replaced every 24 to 48 hours. Culture dishes were seeded with satellite cells and were maintained in a $37^{\circ} \mathrm{C}$ humidified atmosphere of 95\% air with $5 \%$ carbon dioxide.

To prevent satellite cells from premature differentiation and fusion in vitro, frequent passaging (every 48 to 72 hours) was carried out. During the passaging procedure, satellite cells were subjected to a 30-second period of treatment with trypsin (Gibco) diluted 10 times in M199. This measure facilitates detachment of cells from the tissue culture dishes.

Satellite cell labeling and implantation. On the day of implantation, to culture dishes containing satellite cells, a solution of $0.02 \%$ DAPI (Sigma) was added. The dye was allowed to remain in the culture dishes for at least $30 \mathrm{~min}$ utes. The cells were rinsed at least 6 times in Hanks balanced salt solution to remove all excess, unbound DAPI. Satellite cells were then collected (approximately $1 \times 10^{6}$ cells) and resuspended in $50 \mu \mathrm{L}$ of M199.

Thirty male Lewis rats weighing 225 to $250 \mathrm{~g}$ served as the recipients of the DAPI-labeled satellite cells. Anesthesia was induced and maintained with isoflurane (MTC Pharma- 


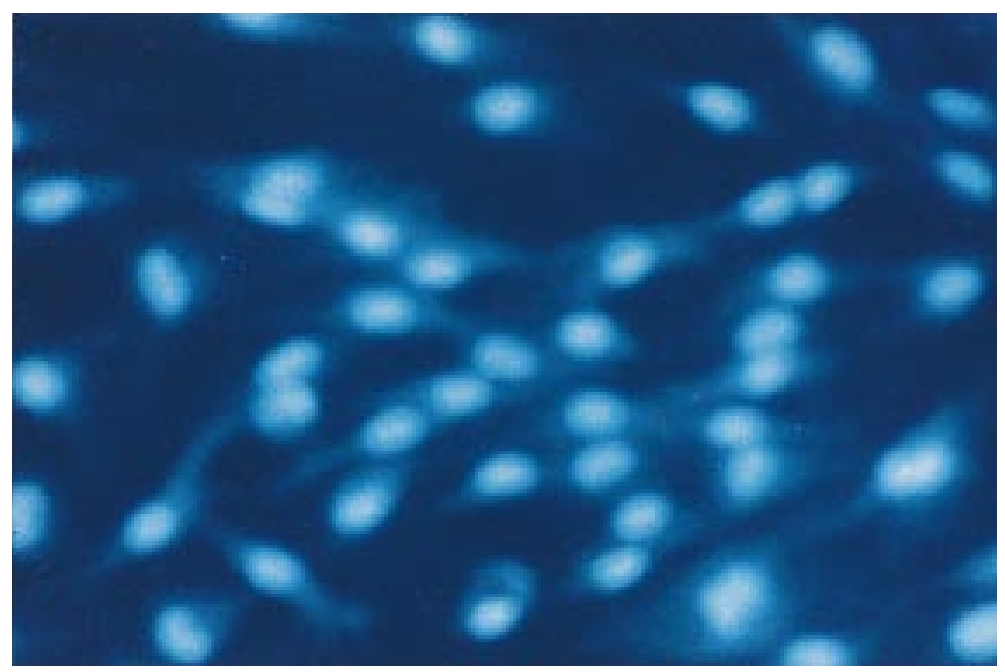

Fig 1. Cultured satellite cells stained with DAPI. Note that virtually $100 \%$ of the cultured cells are labeled.

ceuticals). Animals were intubated with an 18-gauge intravenous catheter and connected to a Harvard rodent ventilator (Harvard Apparatus Co, Inc, South Natick, Mass) at 100 breaths/min. The heart was exposed via a $1.5 \mathrm{~cm}$ left thoracotomy incision. Under direct vision, the satellite cell suspension was injected into the left ventricular wall with a 28 -gauge needle. The thoracotomy was closed with 4-0 monofilament sutures. The muscle and skin layers were closed with 4-0 absorbable sutures, and the animals were returned to their cages. The operative mortality was $20 \%$ (6 animals), caused by ventricular fibrillation after injection of satellite cells. There were no late deaths.

Fluorescence microscopy. One to 4 weeks after implantation, animals were administered an overdose of pentobarbital (100 mg/kg intraperitoneally). Each animal's heart was removed and fixed in $4 \%$ paraformaldehyde (Fisher Scientific International Inc, Hampton, NH). The left ventricle was isolated from the remainder of the heart and embedded in paraffin. The entire left ventricle was sectioned into $5 \mu \mathrm{m}$ specimens and every second section was examined under the fluorescent microscope (absorption at $350 \mathrm{~nm}$, emission at $420 \mathrm{~nm})$.

\section{Results}

The labeling efficiency of cultured satellite cells with DAPI approached 100\% (Fig 1). Culture of satellite cells for up to 1 week, with DAPI added to the culture medium, did not result in a decrease in cell viability. Gross examination of the intact specimen did not reveal any structural abnormalities. The implant site was not evident. Microscopic analysis revealed 4 specimens in which fluorescent cells were identified within the host myocardium. Two specimens were obtained 1 week after implantation and another 2 specimens were obtained 4 weeks after implantation. At 1 week, a mass of fluorescent cells was found at 1 discrete location within the host myocardium (Fig 2). Their primitive structure would imply that these are satellite cells at the original implant site that have not yet differentiated. Near the implant site, however, fluorescent cells with the same structure as the surrounding myocytes were identified (Fig 3). The fluorescent fibers were aligned with the host myocytes. The nucleus of these labeled muscle fibers is centrally located.

At 4 weeks, the undifferentiated cells were no longer present. However, the number of labeled muscle fibers was much greater. As already described, the structure of the labeled cells was the same as that of the surrounding myocytes, and these cells were always aligned with the host myocytes (Fig 3). In the remaining 20 specimens, fluorescent cells were not identified anywhere in the myocardium.

\section{Discussion}

The myocardium develops from cells of the precardiac mesoderm. Differentiation of mesodermal cells into cardiomyocytes is completed very early during development. ${ }^{1}$ Growth of myocytes in the embryo consists of hyperplasia of the existing, differentiated cells. In the early postnatal period, the enzymes needed for DNA synthesis are turned off and the proliferative capacity of the cardiac myocyte is lost. ${ }^{1}$

The lack of proliferative ability of existing myocytes, coupled with the absence of stem cells, accounts for the fact that the myocardium of adult mammals is not able to regenerate. Injury to a portion of the mammalian heart results in an irreversible loss of cells and a permanent loss of function. Transplantation of exogenous cells into the heart is one potential therapeutic 


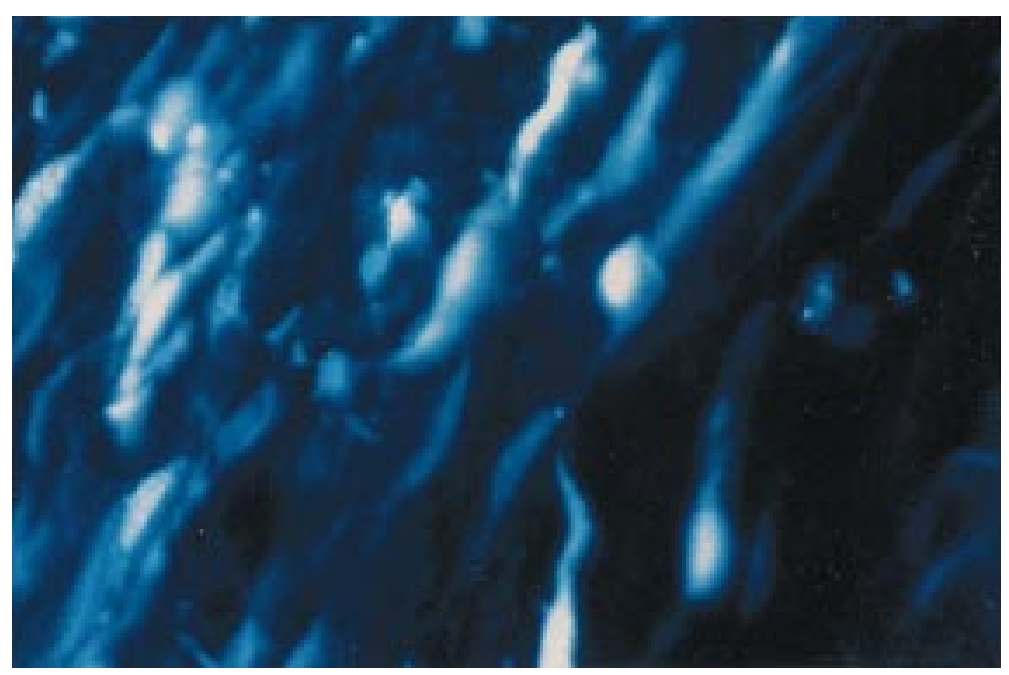

Fig 2. Labeled cells within the host myocardium 1 week after satellite cell implantation. Note undifferentiated appearance of the cells. Location within the myocardium most likely corresponds to the implant site.

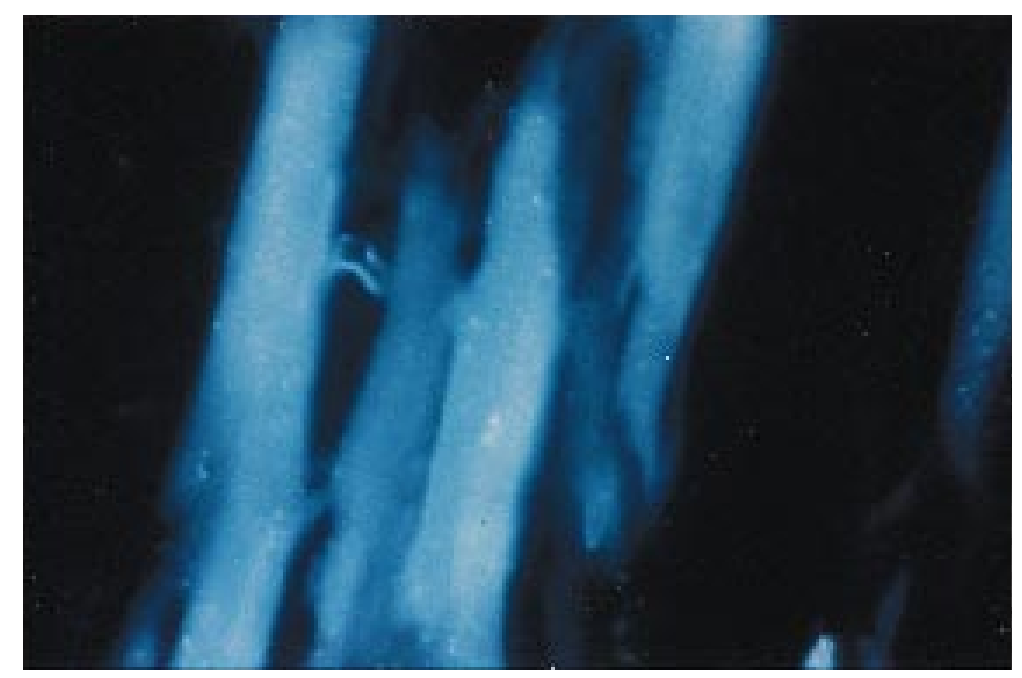

Fig 3. Labeled muscle fibers within host myocardium 1 week after satellite cell implantation. Four fluorescent cells are found clustered together but are interspersed by an unlabeled (host) myocyte. Fluorescent cells have the same structure as the surrounding native myocytes. Similar findings were obtained 4 weeks after satellite cell implantation.

approach for repair of damaged myocardium. The rationale of this strategy is that an increase in the number of muscle fibers will result in an improvement of overall function. A number of cell types are available and have already been used for this purpose. Cardiomyocyte and skeletal myoblast cell lines form stable grafts when transplanted into the myocardium. ${ }^{11-13}$ However, the drawback of these cell types is their potential for malignant transformation. Fetal cardiomyocytes also form stable intracardiac grafts ${ }^{14-16}$ and have been shown to couple with host cells via intercalated disks. ${ }^{17}$ Fetal skeletal myoblasts can also establish new contractile tissue when, transplanted into the myocardium, these grafts convert to fatigue-resistant, slow-twitch fibers that may be more suited to a cardiac workload. ${ }^{18}$ However, the ethical issues involved in the use of fetal tissues would likely limit their practical application.

The satellite cell of skeletal muscle has many properties that make it the ideal cell for restoring lost cardiac 


\section{Image not available}

Fig 4. Histologic study of tissue found at the implantation site, after auto-implantation of canine satellite cells into the myocardial cryolesion. The arrow points to an intercalated disk unique to cardiac myofibers. (From Chiu RC-J, Zibaitis A, Kao RL. Cellular cardiomyoplasty: myocardial regeneration with satellite cell implantation. Reprinted with permission from the Society of Thoracic Surgeons, The Annals of Thoracic Surgery 1995;60:12-8 [Fig 4]).

muscle. Satellite cells are easily obtainable and, inasmuch as they are primary cells, there is no potential for malignant transformation. Satellite cell transplants are autologous; therefore there is no need for immunosuppression and there are no ethical concerns related to the use of fetal tissues. Our hypothesis is that this cell will differentiate into a cardiac myocyte, under appropriate conditions, when transplanted into the heart.

In our first series of experiments, the satellite cells were labeled with ${ }^{3} \mathrm{H}$-thymidine before implantation into acutely cryoinjured myocardium. Gross examination of the implant site revealed muscle-like tissue, and histologic analysis confirmed the presence of striated cells connected by intercalated disks (Fig 4). ${ }^{4}$ However, autoradiographic evaluation of this tissue revealed a labeling intensity almost indistinguishable from background. Marker dilution associated with multiple cell replications before differentiation is a possibility. Attempts to increase initial labeling concentration could perhaps cause radiation injury of the nuclei. In any event, failure to follow the ${ }^{3} \mathrm{H}$-thymidine-labeled satellite cells in vivo did not allow for definitive validation of our original hypothesis and prompted us to use an artificially constructed DNA plasmid as a satellite cell marker.

In a second attempt, satellite cells were transfected with a plasmid carrying the $l a c Z$ reporter gene, which codes for $\beta$-galactosidase, and then implanted into acutely cryoinjured myocardium. ${ }^{4}$ The results of these experiments demonstrated $\beta$-galactosidase activity within the tissue at the implant site. Inasmuch as the satellite cells were transfected with the gene coding for this enzyme before implantation, this finding confirmed that the satellite cells survived (Fig 5). Unfortunately, so far we have been unsuccessful in demonstrating satellite cell differentiation into fully developed muscle fibers. Failure to detect labeled muscle fibers at the implant site may be due to altered expression of the lac $Z$ reporter gene by fully differentiated muscle fibers, perhaps caused by the loss of the genes or their promoters. Another concern with the use of this particular plasmid construct was that the transfection efficiency of satellite cells was quite low (10\%-20\%).

Thus our previous work confirmed survival of the implanted, labeled satellite cells. Furthermore, striated muscle fibers were demonstrated histologically at the original satellite cell implant site. ${ }^{4,19}$ Nevertheless, definitive proof of "milieu-dependent" satellite cell differentiation was not achieved owing to the absence of fully developed muscle fibers carrying the original satellite cell marker. In a continued effort to validate our original hypothesis, we sought a new satellite cell marker that would ideally have the following properties: (1) high labeling efficiency, (2) expression of cell marker not altered by state of differentiation of a cell, and (3) stable cell marker retained by satellite cells throughout 


\section{Image not available}

Fig 5. Implanted satellite cells encoded with the lacZ reporter gene; note $\beta$-galactosidase activity at the implant site within the myocardium. (From Chiu RC-J, Zibaitis A, Kao RL. Cellular cardiomyoplasty: myocardial regeneration with satellite cell implantation. Reprinted with permission from the Society of Thoracic Surgeons, The Annals of Thoracic Surgery 1995;60:12-8 [Fig 6]).

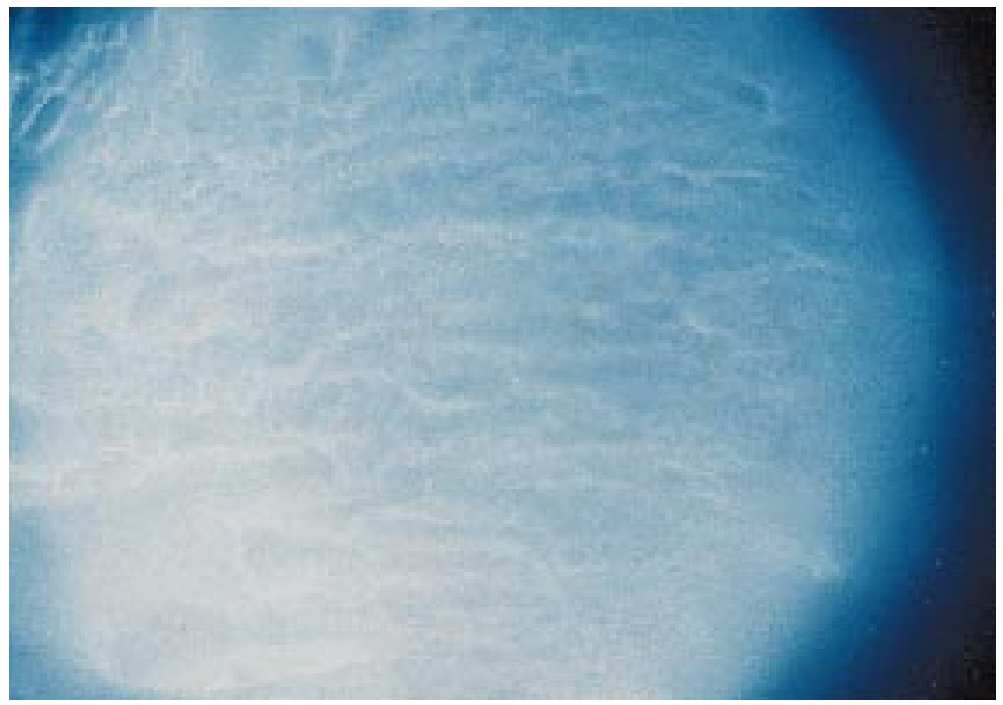

Fig 6. Direct injection of DAPI solution into a muscle tissue in vivo failed to show uptake of DAPI fluorescence in a specimen obtained 1 week after injection.

their development in vivo. DAPI is a fluorescent dye that labels the nucleus of a cell because of its high affinity for dsDNA. ${ }^{8}$ Its mechanism of action is that it forms strong electrostatic interactions with adenine-thymine rich regions of DNA. The fluorescence quantum yield of the free dye is very low, but its binding to DNA results in a highly fluorescent complex. The other cell component to which DAPI binds to form a fluorescent complex is the protein tubulin. ${ }^{9}$ DAPI is nontoxic to living cells and does not alter the ultrastructure of cell organelles. ${ }^{7}$

To further validate the use of DAPI as the cell marker for our study, we did additional experiments to expel the concern that some leakage of the dye into the surrounding milieu could give false positive results. Accordingly, we injected DAPI solution directly into the muscle to see whether in vivo uptake would occur. As 


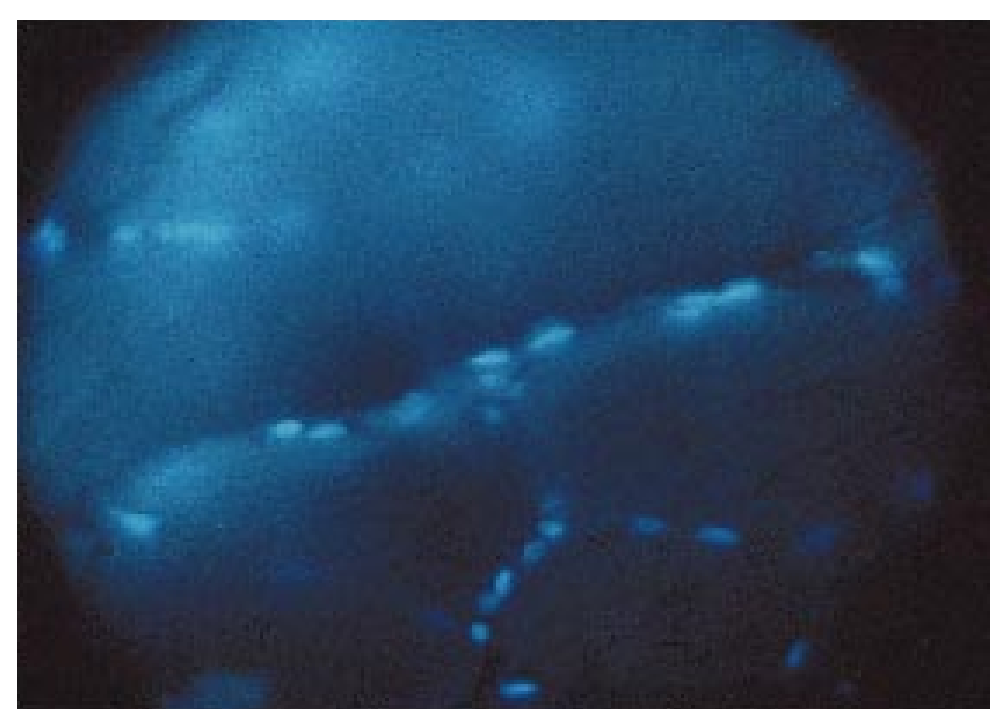

Fig 7. Satellite cells labeled in vitro with DAPI while in culture were implanted in the skeletal muscle of the isogenic rats. This specimen obtained 4 weeks later demonstrates labeled nuclei that are characterized by their spindle shape and located peripherally in a multinuclear muscle fiber, characteristic of the skeletal muscle fiber structure.

shown in Fig 6, no muscle fiber with positive DAPI fluorescence was noted. It is likely that this is due to the rapid washout of injected dye from the tissue by the blood flow, which did not allow sufficient time for DAPI to bind to the DNA in the nuclei. As mentioned earlier, the DAPI solution is incubated in vitro with cultured cells for a period of 30 minutes or more in our study, as well as those by others. ${ }^{7}$ The excess dye in the cultured media was removed before cell implantation.

If DAPI can label satellite cells in vitro without preventing the labeled cells from differentiating, it is reasonable to expect that implantation of such cells into skeletal muscle should produce skeletal muscle fibers with labeled nuclei. Such an experiment was also carried out as another step in validating our method. As shown in Fig 7, 4 weeks after the implantation of DAPI-labeled satellite cells into the skeletal muscle, labeled multinucleated muscle fibers were seen in the specimen. These fibers contained spindle-shaped nuclei located in the periphery of the muscle fibers, demonstrating morphologic characteristics of skeletal muscle fibers, which are distinct from those seen in Fig 3. The specimen shown in Fig 3 is taken from myocardium, and the labeled muscle fibers seen contain vesicular and centrally located nuclei, similar to those in the cardiac muscle fibers.

In this study, the satellite cells were injected into the beating heart with a needle in an open chest rat. Because the needle hole was not sealed, it is possible that much of the implanted cells had been squeezed out from the ventricular wall during systolic compression by the surrounding muscle fibers. This may explain in part why we found only 4 hearts with positively labeled myofibers out of 20 implantations. To achieve greater consistency, we are pursuing further refinement and optimization of culture and implantation techniques.

\section{Conclusion}

Our results indicate that DAPI is a useful marker to follow the development of satellite cells in vivo. The dye is stably incorporated by the satellite cell and persists within the cell throughout its development within the host myocardium. Using DAPI as a marker, we were again able to confirm satellite cell survival within the myocardium. Furthermore, our finding of labeled, fully differentiated muscle fibers strengthens and supports the hypothesis that skeletal myoblasts do in fact differentiate into muscle fibers after transplantation into the myocardium. Our earlier morphologic studies also indicated that such new tissue may express phenotypes ranging from those of cardiac, skeletal, and even "mosaic" muscle fibers, depending on the culture and implant conditions. ${ }^{6}$ Further phenotype characterization at the molecular level is currently being undertaken with the use of phenotype-specific monoclonal antibodies.

\section{REFERENCES}

1. Rumyantsev PP. Interrelations of the proliferation and differentiation processes during cardiac myogenesis and regeneration. Int Rev Cytol 1977;51:187-273.

2. Dorfman J, Kao RL. Myocardial growth and regeneration: an 
overview. In: Kao RL, Chiu RC-J, editors. Cellular cardiomyoplasty: myocardial repair with cell implantation. Austin: Landes Bioscience; 1997. p. 1-25.

3. Mauro A. The satellite cell of skeletal muscle fibers. J Biophys Biochem Cytol 1961;9:493-5.

4. Chiu RC-J, Zibaitis A, Kao RL. Cellular cardiomyoplasty: myocardial regeneration with satellite cell implantation. Ann Thorac Surg 1995;60:12-8.

5. Marelli D, Desrosiers C, El-Alfy C, Kao RL, Chiu RC-J. Cell transplantation for myocardial repair: an experimental approach. Cell Transplant 1992;1:383-90.

6. Zibaitis A, Ma F, Duong M, Chiu RC-J. Cellular cardiomyoplasty: results and possibility for the future. Cardiovasc Eng 1996;1:55-9.

7. Tarnowski BI, Spinale FG, Nicholson JH. DAPI as a useful stain for nuclear quantitation. Biotech Histochem 1991;66:296-302.

8. Kapuscinski J. DAPI: a DNA-specific fluorescent probe. Biotech Histochem 1995;70:220-33.

9. Bonne D, Heusele C, Simon C, Pantaloni D. 4',6-diamidino-2phenylindole, a fluorescent probe for tubulin and microtubules. J Biol Chem 1985;260:2819-25.

10. Yablonka-Reuveni Z, Nameroff M. Skeletal muscle cell populations: separation and partial characterization of fibroblast-like cells from embryonic tissue using density centrifugation. Histochemistry 1987;87:27-38.

11. Koh GY, Klug MG, Soonpah MH, Field LJ. Differentiation and long-term survival of $\mathrm{C} 2 \mathrm{C} 12$ myoblast grafts in heart. J Clin Invest 1993;92:1548-54.

12. Koh GY, Soonpah MH, Klug MG, Field LJ. Long-term survival of AT-1 cardiomyocyte grafts in syngeneic myocardium. Am J Physiol 1993;264:H1727-33.

13. Robinson SW, Cho PW, Levitsky HI, Olson JL, Hruban RH, Acher MA, et al. Arterial delivery of genetically labeled skeletal myoblasts to the murine heart: long-term survival and phenotypic modification of implanted myoblasts. Cell Transplant 1996;5:77-91.

14. Connold AL, Frischknecht R, Dimitrakos M, Vrbova G. The survival of embryonic cardiomyocytes transplanted into damaged host rat myocardium. J Muscle Res Cell Motil 1997;18:63-70.

15. Koh GY, Soonpah MH, Klug MG, Pride HP, Cooper BJ, Zipes DP, et al. Stable fetal cardiomyocyte grafts in the hearts of dystrophic mice and dogs. J Clin Invest 1995;96:2034-42.

16. Li RK, Jia ZQ, Weisel RD, Mickle DAG, Zhang J, Mohabeer MK, et al. Cardiomyocyte transplantation improves heart function. Ann Thorac Surg 1996;62:654-61.

17. Soonpah MH, Koh GY, Klug MG, Field LJ. Formation of nascent intercalated discs between grafted fetal cardiomyocytes and host myocardium. Science 1994;264:98-101.

18. Murry CE, Wiseman RW, Schwartz SM, Hauschka SD. Skeletal myoblast transplantation for repair of myocardial necrosis. J Clin Invest 1996;98:2512-23.

19. Kao RL, Chiu RC-J. Satellite cell implantation. In: Kao RL, Chiu RC-J, editors. Cellular cardiomyoplasty: myocardial repair with cell implantation. Austin: Landes Bioscience; 1997. p. 129-62.

\section{Discussion}

Dr Juan C. Chachques (Paris, France). I want to congratulate the group of Dr Chiu for this continued work in cellular cardiomyoplasty. The European Union selected our group at Broussais Hospital in Paris to develop a similar cell implant program, which we call "dynamic cellular cardiomyoplasty," because we think that the implanted cell must contribute to myocardial contractility.

I have 2 questions. First, do you think that the myocardial depolarization will be sufficient to induce contraction of your implanted cells, or perhaps in the future would it be necessary to electrically stimulate this new tissue? Second, concerning the cells marked with DAPI, it will be interesting to know whether this product will be released and whether there is a risk of toxicity for the cell itself.

Dr Dorfman. I think it is possible that these cells can couple with the surrounding myocytes. In a work published in 1996, in which myoblast cell lines were implanted into the myocardium, the investigators found structures that looked like gap junctions between the implanted and the native myocytes, and they were able also to stain for connexin-43, which is a gap junction at the interface of the implanted and host myocytes.

In answer to your second question, this marker works by diffusing into the cell down its concentration gradient and forming a very strong electrostatic interaction with dsDNA. We cultured cells with this dye for a long time. It is stably retained by the cell even at very high concentrations, and it is not toxic to the cell. It can also bind to other components of the cell. For example, it binds with tubulins with which it also fluoresces. When it binds to RNA, however, the complex is not fluorescent. The free dye itself is also not fluorescent. It is very specific for dsDNA and for tubulins.

Mr Magdi Yacoub (London, United Kingdom). Central to your hypothesis is the expression by these cells of myocardium-specific functional type proteins, for example, dihydropteridine, myocardium-specific isoforms, or gap junctions specific to the myocardium such as connexin-43. Can you reassure us that these indeed are myocytes rather than skeletal type cells, which are two different things?

Dr Dorfman. No, we have not reached that stage yet to determine the exact phenotype of these cells.

Dr Eric A. Rose (New York, NY). I will ask what I think would be the question of the Toronto group: They are telling us now that the terminal differentiation "religion" that we are working with is incorrect, that myocytes can be isolated and propagated in culture. Have you tried to do that?

Dr Dorfman. We have not tried to do that, because from my research and from reading the literature, I was convinced that the cardiac myocyte is truly a terminally differentiated cell. If these cells could be propagated in culture, I would be concerned about them being transformed in some way.

Dr Alain F. Carpentier (Paris, France). Why did you not use cryoinjury before the implantation of the cells? Were you afraid of fibrous proliferation? What is your rationale for not trying to mimic myocardial injury?

Dr Dorfman. I wanted the satellite cells to be exposed as much as possible to the cardiac environment rather than in a scar that contains fibroblasts and inflammatory cells. I thought that would give me the greatest chance for success. 